\title{
A case of primary lymphoma of the liver
}

\author{
T. J. CHAMBERS, D. P. O'DONOGHUE, AND A. G. STANSFELD \\ From the Departments of Histopathology and Gastroenterology, St Bartholomew's Hospital, \\ London ECIA $7 B E$
}

SYNOPSIS A case of primary malignant lymphoma of the liver is described. Presenting with epistaxis, he died in hepatic encephalopathy with an intractable bleeding post-bulbar duodenal ulcer.

\begin{abstract}
Although lymphomatous involvement of the liver is common in generalized lymphoma, lymphoma confined to the liver is exceptionally rare. Only three previous cases have been documented. The case described here is also unusual in being complicated by bleeding from a post-bulbar duodenal ulcer.
\end{abstract}

\section{Case report}

A 55-year-old bank official presented at his local hospital with a severe epistaxis. He gave a six-week history of fatigue, anorexia, and loss of weight. His wife had noticed that at times he was confused and his speech was slurred.

In 1945 he had developed malaria. This was treated routinely and there were no recurrences. Splenomegaly was noted at that time. There was no history of excess alcohol intake.

On examination there was hepatosplenomegaly and he was admitted for further investigation. Over the next 48 hours he passed both fresh and altered blood per rectum. The prothrombin time and platelet count were normal, but his haemoglobin was 6.3 $\mathrm{g} / \mathrm{dl}$. Barium studies showed a post-bulbar duodenal ulcer and possible oesophageal varices. He was transfused 11 units of blood and transferred to St Bartholomew's Hospital.

Examination on admission revealed a confused man with a marked flapping tremor and extrapyramidal rigidity. Foetor hepatis was present. There was no bruising of the skin nor petechial haemorrhages. Hepatosplenomegaly was present but there was no lymphadenopathy. None of the stigmata of chronic liver disease was present.

Investigations at this time showed a post-transfusion haemoglobin of $13 \mathrm{~g} / \mathrm{dl}$, white cell count of 3800 cells $/ \mathrm{mm}^{3}$, and a platelet count of $108000 /$ $\mathrm{mm}^{3}$. Blood urea and serum electrolytes were normal.

Received for publication 23 March 1976
Total protein was $4 \cdot 4 \mathrm{~g} / \mathrm{dl}$, of which $2 \cdot 3$ was albumin. The bilirubin was $2.7 \mathrm{mg} / \mathrm{dl}$, the alkaline phosphatase $575 \mathrm{IU} / 1$, and the serum aspartate aminotransferase was $273 \mathrm{IU} / 1$.

It was thought that he had cirrhosis of the liver, and in view of the severity of his liver dysfunction no surgery was undertaken initially. Routine measures to combat hepatic encephalopathy were started but no improvement was noted. Six days after admission he again passed a melaena stool and became clinically shocked. Emergency endoscopy showed that the bleeding was from a post-bulbar duodenal ulcer. Oesophageal varices were not seen.

At laparotomy later the same day the ulcer, measuring $2 \times 1 \mathrm{~cm}$, was located on the medial aspect of the second part of the duodenum. This was oversewn and a truncal vagotomy and Finney pyloroplasty were performed. The liver had a strange mottled appearance and a wedge biopsy was taken before the abdomen was closed.

Postoperatively the patient failed to regain consciousness and continued to lose blood from the gastrointestinal tract. There was no evidence of disseminated intravascular coagulation. He failed to respond to transfusions of fresh blood and fresh frozen plasma and died 36 hours later.

At necropsy the liver weighed $2105 \mathrm{~g}$ and showed pale nodules alternating with rather haemorrhagic areas throughout almost its entire substance (fig 1). The nodules measured up to $3 \mathrm{~mm}$ in diameter, were of firm consistency, and in some areas coalesced to form collections of nodules. The spleen was enlarged $(830 \mathrm{~g})$ but showed no macroscopic tumour on fine slicing. No enlarged lymph nodes were found. The red marrow showed some extension into the distal third of the femur but appeared qualitatively normal throughout the vertebral column, sternum, and femur. There was fairly extensive bleeding into the musculature of the right chest wall, axilla, and shoulder. The pyloroplasty suture line was intact and 


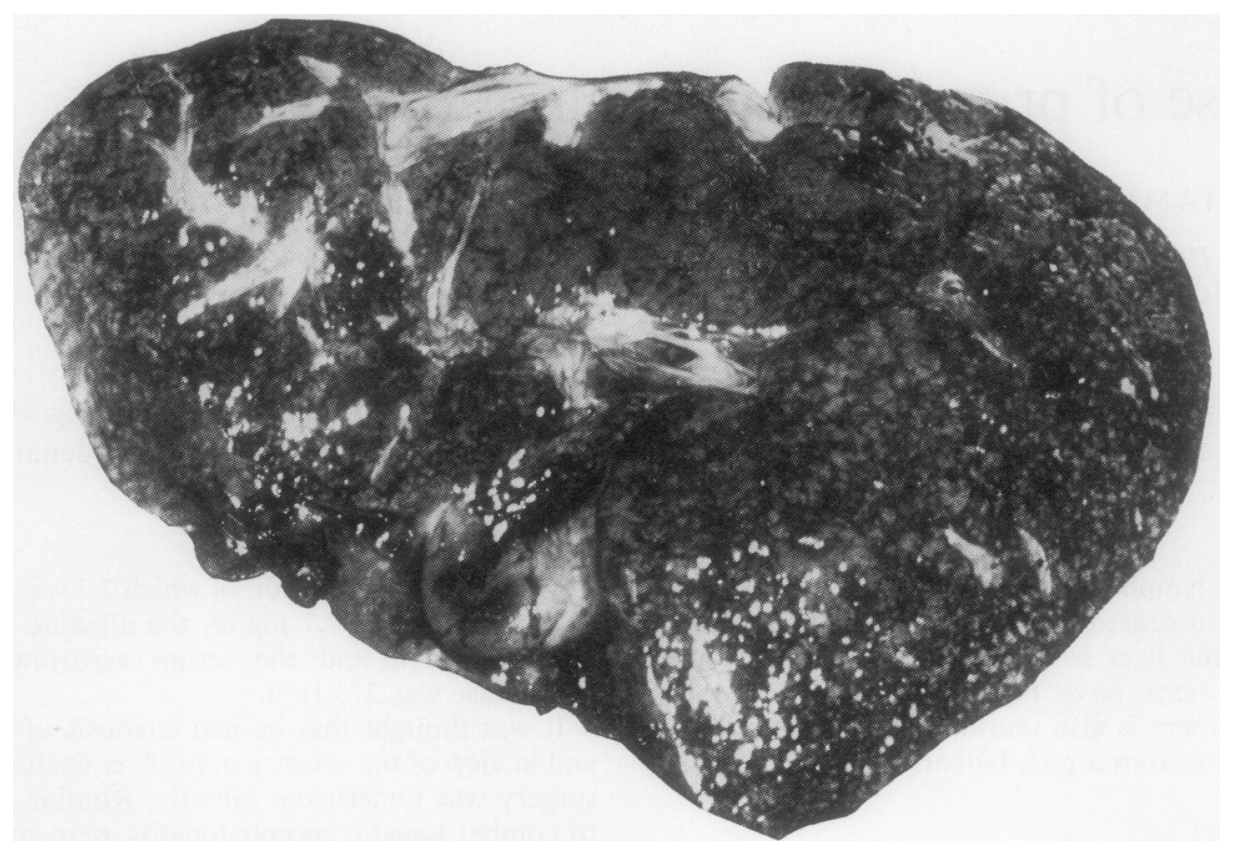

Fig 1 The liver at necropsy showing pale lymphoma deposits throughout.

a shallow ulcer in the second part of the duodenum was oversewn. However, blood appeared to have continued to ooze from this site, and the whole length of the gastrointestinal tract below the oesophagus contained fresh or altered blood. The duodenum and remainder of the gastrointestinal tract were otherwise normal.

Histological examination of the liver (figs 2 and 3) showed the pale areas to consist of loose collections of lymphoid cells with large pleomorphic nuclel, many showing nucleoli. The cells were lying singly or in groups and showed a relatively thin rim of pale cytoplasm round their large nuclei. There was no evidence of the formation of intercellular substance, nor did the cells show an inclination for intercellular adhesion. There were several mitoses per highpower field, and many of the mitoses were of abnormal configuration. The cells preferentially clustered around portal areas, and the haemorrhagic areas were confined mainly to centrilobular areas of the liver. The appearances were quite unlike those of a hepatitis, tracts of liver parenchyma showing no inflammatory infiltrate or other abnormality between areas of large, bizarre pleomorphic lymphoid cells. There was no doubt that the tumour was a malignant lymphoma. The widespread necrosis and pleomorphism made classification difficult but indicated a lymphoma of high-grade malignancy.

No lymphoma was found in sections from any other organs, particularly those of lymph node spleen, bone marrow, ulcer base or central nervouss system.

\section{Discussion}

Apart from its usual origin in lymph nodes, spleen $\frac{\bar{\partial}}{3}$ and bone marrow, lymphoma has been less frequently reported to originate in the stomach, intes tine, lung, skin, thyroid, orbit, brain, testis, breast and kidney.

In contrast, Torres (Torres, 1969; Torres ando Bollozos, 1971), in reporting two cases of primary? lymphoma of the liver, states that no previous caseo had been reported. A thorough review of the litera ture has revealed only one further case (Ata and Kamal, 1965). This is somewhat surprising, for tak $\rightarrow$ ing into account the bulk of the liver, there is a cono는 siderable total mass of lymphoid tissue in the portah tracts from which a lymphoma could arise.

Although secondary involvement of the liver in lymphoma is common, the liver does not seem to be of preferred site for the growth of lymphoma. Thus, ino two large series of patients subjected to systematic laparotomy and splenectomy in Hodgkin's disease no instance of liver involvement was noted withouf? concomitant splenic involvement (Glatstein et $a l ; 0$ 1970; Zarembok et al, 1972).

In the absence of evidence of lymphoma elsewhere 


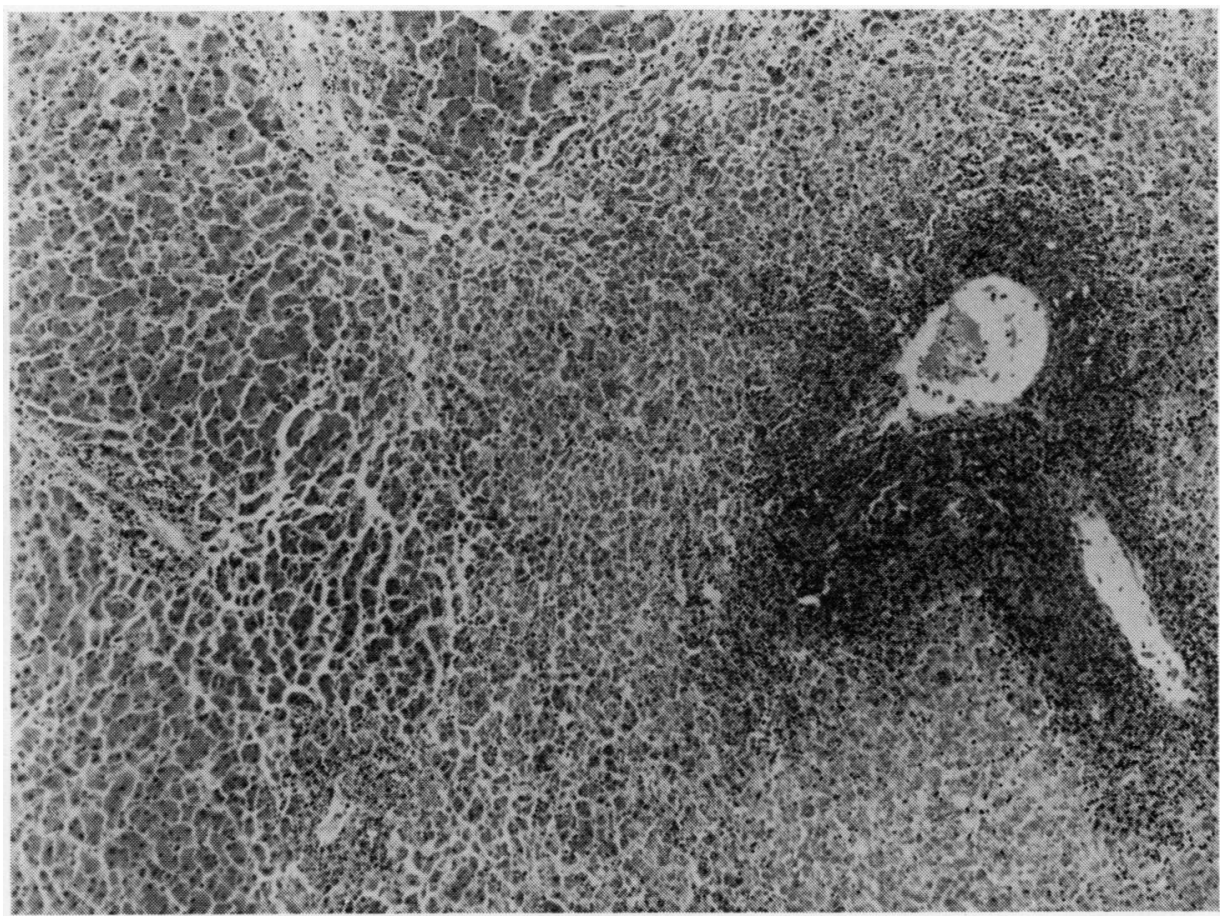

Fig 2 To the left can be seen uninvolved liver. On the right is a mass of hyperchromatic cells surrounding a central vein. Haematoxylin and eosin $\times 40$.

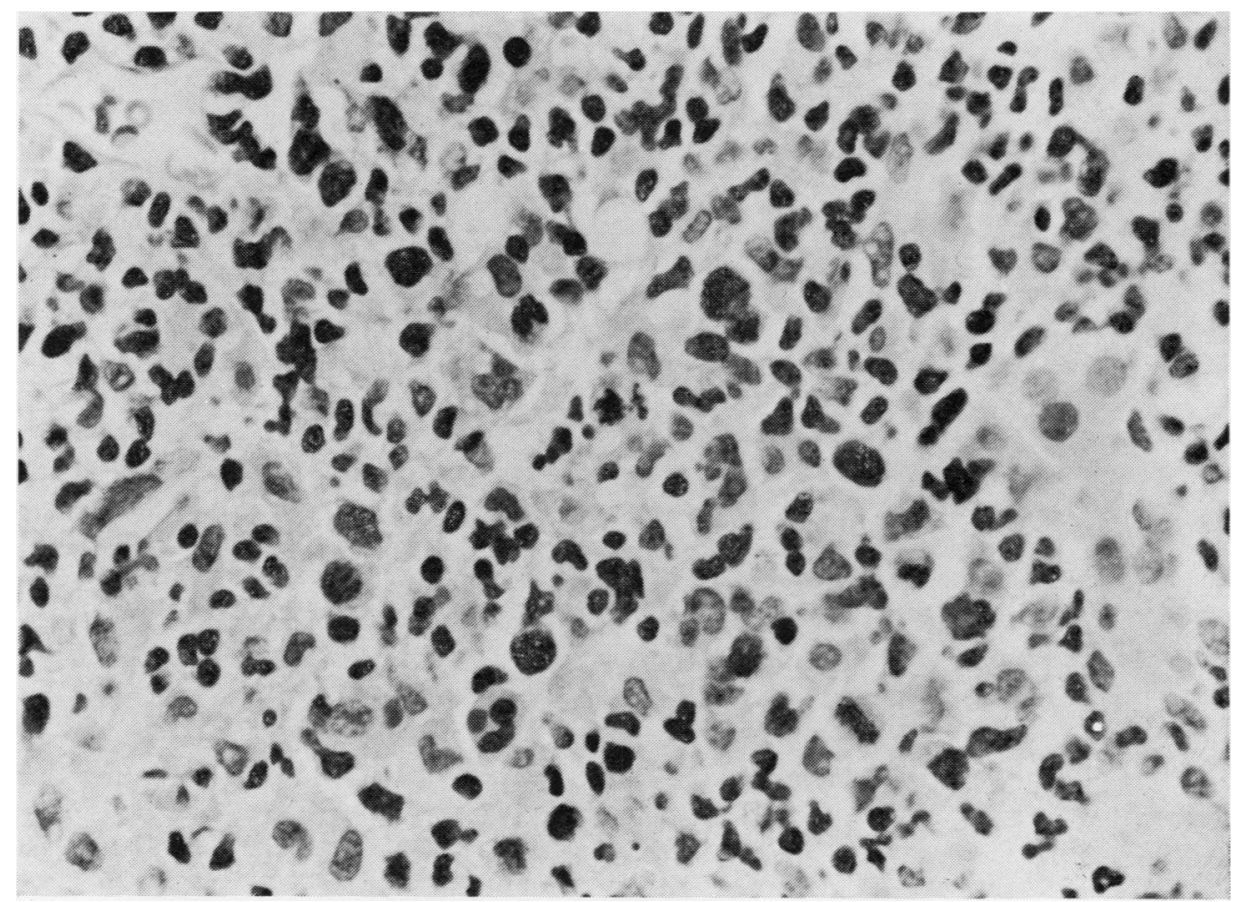

Fig 3 A high-power view of a nodule shows the pleomorphic cells with hyperchromatic nuclei and many mitoses, some of which are abnormal. Haematoxylin and eosin $\times 400$. 
this disease must be one of the rarest causes of liver failure. Fairbank (1953) was able to report the first three cases of liver failure as a presentation of Hodgkin's disease. Although there were no antemortem grounds for suspecting lymphoma, necropsy revealed lymphomatous involvement of the liver, but in each case the spleen and either abdominal or mediastinal lymph nodes were also involved.

In the case we report here, hepatic encephalopathy was a feature of the patient's illness throughout his time in hospital and may well have been one of its first manifestations as judged by the presenting story of confusion and dysarthria. The immediate cause of death was loss of blood from a coincidental peptic ulcer, which presumably aggravated the manifestations of liver failure.

We should like to thank $\operatorname{Dr}$ A. M. Dawson for his advice in the preparation of this paper.

\section{References}

Ata, A. A. and Kamal, I. A. (1965). Primary reticulum cell sarcoma of the liver; a case report. J. Egypt med. Ass., 48, 514-521.

Fairbank, W. H. D. (1953). Three atypical cases of Hodgkin's disease, presenting with liver failure. Canad. med. Ass. J., 69, 315-317.

Glatstein, E., Trueblood, H. W., Enright, L. P., Rosenberg, S. A., and Kaplan, H. S. (1970). Surgical staging of abdominal involvement in unselected patients with Hodgkin's disease. Radiology, 97, 425-432.

Torres, A. (1969). Primary lymphocytic follicular lymphoma of liver. Cancer (Philad.), 23, 1185-1189.

Torres, A. and Bollozos, G. D. (1971). Primary reticulum cell sarcoma of liver. Cancer (Philad.), 27, 1489-1492.

Zarembok. I., Ramsey, H. E., Sutherland, J., and Serpick, A. A. (1972). Laparotomy and splenectomy in the staging of untreated patients with Hodgkin's disease. Radiology, 102, 673-689. 